\title{
Scaling for turbulent viscosity of buoyant plumes in stratified fluids: PIV measurement with implications for submarine hydrothermal plume turbulence
}

\author{
Wei Zhang ${ }^{1,2}$, Zhiguo $\mathrm{He}^{1}$, Houshuo Jiang ${ }^{2 *}$ \\ ${ }^{1}$ Institute of Coastal and Offshore Engineering, Ocean College, Zhejiang University, Zhoushan, \\ 316021, China \\ ${ }^{2}$ Department of Applied Ocean Physics and Engineering, Woods Hole Oceanographic Institution, \\ Woods Hole, MA 02543, USA
}

*Author for correspondence

(E-mail: hsjiang@whoi.edu; Tel.: +1 508289 3641; Fax: +1 508457 2194)

Submitted to Deep-Sea Research Part I: Oceanographic Research Papers on Jan. 8, 2017.

Major revision submitted to Deep-Sea Research Part I: Oceanographic Research Papers on July 25, 2017.

Accepted for publication on October 7, 2017.

Published online on October 14, 2017.

Zhang, W., He, Z. and Jiang, H. (2017) Scaling for turbulent viscosity of buoyant plumes in stratified fluids: PIV measurement with implications for submarine hydrothermal plume turbulence. Deep-Sea Research Part I: Oceanographic Research Papers, 129, 89-98. https://doi.org/10.1016/j.dsr.2017.10.006 


\begin{abstract}
Time-resolved particle image velocimetry (PIV) has been used to measure instantaneous twodimensional velocity vector fields of laboratory-generated turbulent buoyant plumes in linearly stratified saltwater over extended periods of time. From PIV-measured time-series flow data, characteristics of plume mean flow and turbulence have been quantified. To be specific, maximum plume penetration scaling and entrainment coefficient determined from the mean flow agree well with the theory based on the entrainment hypothesis for buoyant plumes in stratified fluids. Besides the well-known persistent entrainment along the plume stem (i.e., the "plumestem' entrainment), the mean plume velocity field shows persistent entrainment along the outer edge of the plume cap (i.e., the 'plume-cap' entrainment), thereby confirming predictions from previous numerical simulation studies. To our knowledge, the present PIV investigation provides the first measured flow field data in the plume cap region. As to measured plume turbulence, both the turbulent kinetic energy field and the turbulence dissipation rate field attain their maximum close to the source, while the turbulent viscosity field reaches its maximum within the plume cap region; the results also show that maximum turbulent viscosity scales as $v_{t, \max }=0.030$ $(B / N)^{1 / 2}$, where $B$ is source buoyancy flux and $N$ is ambient buoyancy frequency. These PIV data combined with previously published numerical simulation results have implications for understanding the roles of hydrothermal plume turbulence, i.e. plume turbulence within the cap region causes the 'plume-cap' entrainment that plays an equally important role as the 'plumestem' entrainment in supplying the final volume flux at the plume spreading level.
\end{abstract}

Keywords: hydrothermal plume turbulence, 'plume-cap' entrainment, turbulent viscosity, timeresolved particle image velocimetry 


\section{Introduction}

Hydrothermal plumes above seafloor vents are Nature's examples of turbulent buoyant plumes in stratified fluids. They are formed from intensive mixing between hot, extremely buoyant fluids discharged from vents and cold, dense, weakly stratified ambient seawater (Lupton et al., 1985; Speer and Rona, 1989; Baker et al., 1995). The discharged hydrothermal vent fluids rise up rapidly and entrain and mix with ambient seawater to form turbulent buoyant plumes. Because the discharged fluids are diluted tremendously by factors of $10^{4}-10^{5}$ (Lupton et al., 1985), a soformed plume will become less and less buoyant while rising. It will eventually lose its buoyancy, reach maximum rise height typically up to 200 - $400 \mathrm{~m}$ above seafloor (Speer and Rona, 1989), and spread laterally along the neutrally buoyant layer with a spatial scale of more than tens of kilometers (Baker et al., 1995).

Investigating plume hydrodynamics and mixing and transport processes is essential to quantitatively understand the connection between oceanic lithosphere and the ocean as well as the impact of hydrothermal plumes on the ocean. Important topics include heat and chemical fluxes issued by vents, abyssal water masses conveyed upward by plumes, and transport and dispersal of microbes and larvae of vent organisms (Baker et al., 1995; Helfrich and Speer, 1995; Mullineaux and France, 1995; Elderfield and Schultz, 1996; German and Lin, 2004; Tagliabue et al., 2010; Dick et al., 2013). On the other hand, investigating turbulence of rising hydrothermal plumes is highly relevant to the study of active hydrothermal systems as vent sites are typically located by detecting their associated rising plumes. Thus, a better understanding of the spatial and temporal characteristics of buoyant plume turbulence can potentially improve our capability of locating active vent sites. The classical fluid dynamics theory for a buoyant plume in a stratified fluid (Morton et al., 1956; Turner, 1973) has successfully informed the evaluation of hydrothermal heat and mass fluxes (Speer and Rona, 1989; Rudnicki and Elderfield, 1992). The theory, however, is not able to inform on buoyant plume turbulence. Nevertheless, buoyant plume turbulence causes transport and mixing that produce the neutrally buoyant plume fluids, thereby affecting the ocean over a wide range of time and length scales (Thurnherr and St. Laurent, 2012). To be more specific, although turbulent entrainment along the plume stem plays the major role in bringing ambient seawater into the plume and causing the plume to rise up to a maximum height, it is the turbulent transport and mixing within the plume cap region that plays the major role in mixing and homogenizing the seawater masses entrained from both below and 
above the plume cap region, to ultimately form the neutrally buoyant plume water. Since the vent fluids are rich in dissolved metals and other chemicals (Von Damm, 1995; German and Von Damm, 2003), buoyant plume turbulence also impacts ocean biogeochemistry through mediating many vent-related biogeochemical processes.

Computational fluid dynamics (CFD) has been used to simulate a rising hydrothermal plume, based on field measurements of vent conditions and background stratification, and to compute characteristics of buoyant plume turbulence, including fields of mean flow, turbulent kinetic energy, turbulence dissipation rate, and turbulent viscosity and diffusivity (Jiang and Breier, 2014). The simulated plume vertical velocity, turbulent mixing, and the geometry of the rising plume have been used to drive a mathematical model for processes that regulate coupled microbial-geochemical dynamics in the plume (Reed et al., 2015). Moreover, the CFD simulation results have suggested a scaling relationship for maximum turbulent viscosity $\left(v_{t, \max }\right)$ :

$$
v_{t, \max }=C_{t}(B / N)^{1 / 2}
$$

where $B$ is source buoyancy flux, $N$ is ambient buoyancy frequency, and $C_{t}$ is constant scaling coefficient.

With a focus on buoyant plume turbulence, we present a series of laboratory experiments on a turbulent buoyant plume in linearly stratified saltwater, using time-resolved particle image velocimetry (PIV) for flow visualization and measurement. Similar laboratory experiments without PIV have been previously conducted to investigate various topics in fluid mechanics of buoyant plumes (Helfrich and Battisti, 1991; Contini et al., 2011; Carazzo et al., 2013; Camassa et al., 2016). Besides, a noninvasive method, called optical plume velocimetry (OPV), has been developed to measure fluid flow rates through laboratory-simulated hydrothermal vents based on image analysis of effluent video (Crone et al., 2008). On the other hand, PIV, as a nonintrusive measurement method, has been widely used for quantitative flow visualization and velocity measurement (Raffel et al., 2007; Adrian and Westerweel, 2011), including applications to oceanic and environmental flows (e.g., Bertuccioli et al., 1999; Doron et al., 2001; HornerDevine, 2006; Seol et al., 2007; Steinbuck et al., 2010). The PIV technique has been previously applied to measure flow velocities of turbulent buoyant plumes generated either thermally (e.g., Pham et al., 2005; Watanabe et al., 2005; Grafsrønningen et al., 2011) or with salinity contrast (Diez et al., 2005). However, all the measurements have been done for plumes in non-stratified fluids. Thus, the aim of the present study is to investigate characteristics of buoyant plume 
turbulence in linearly stratified saltwater. Specifically, we apply time-resolved PIV to measure the two-dimensional (2D) velocity vector field of a turbulent buoyant plume in linearly stratified saltwater over an extended period of time. From the PIV data, we quantify characteristics of the mean flow field and turbulence field of the plume. We also derive the scaling relationship for plume turbulent viscosity, and compare it with the scaling relationship derived previously by the CFD study.

\section{Material and methods}

\subsection{Experimental setup and general data analysis procedure}

All experiments were conducted in the Laboratory of Ocean Engineering at Zhejiang University, using a cubic Plexiglas tank of dimension $50 \times 50 \times 50 \mathrm{~cm}$ (Fig. 1). The tank size, although small, was similar to those used in previous tank experiments of a turbulent buoyant plume in linearly stratified saltwater (e.g., Morton et al., 1956; Turner, 1986; Helfrich and Battisti, 1991). Despite significant size differences between plumes generated in a tank and naturally occurring seafloor hydrothermal plumes, fluid dynamical investigation of turbulent buoyant plumes via tank experiments is considered relevant to the understanding of hydrothermal plume hydrodynamics, turbulence, mixing, and transport. The underlying notion is that the two types of plumes, although very different in size, share a similar turbulent nature of the entrainment process, with regard to both the engulfment of ambient fluid by turbulent eddies along the plume edge and the turbulence inside the plume (Turner, 1986; Hunt and Van den Bremer, 2011).

All experiments were conducted in a room with temperature maintained at $\sim 18^{\circ} \mathrm{C}$. In the beginning of each experimental run, the tank was gradually filled to a depth of $47 \mathrm{~cm}$ with artificial seawater by using the two-tank method to form a linearly stratified saltwater column (Fortuin, 1960; Ghajar and Bang, 1993; Economidou and Hunt, 2009). A nozzle of 5 or 7 mm inner diameter was mounted at the center of a supporting rail that was fixed on the top of the tank. The nozzle was used to inject dense saltwater vertically downward into the stratified saltwater at a location $\sim 3 \mathrm{~cm}$ below the fluid surface. A flow meter and a pump were used to maintain a constant flow rate for each experimental run. Small amounts of fluid samples were extracted from eight needles whose tips were located at different depths along the tank wall. The needles were numbered 1 through 8 from the top to the bottom; Needle 1 was at the surface, 
Needle 2 was $\sim 3 \mathrm{~cm}$ below the surface, which was used to sample the fluid at the level of the nozzle, Needle 3 was located $\sim 4 \mathrm{~cm}$ below Needle 2, and Needles 3 through 8 were spaced one by one $\sim 8 \mathrm{~cm}$ apart with Needle 8 sitting on the bottom. The salinity at each depth was measured and density calculated from a fitted equation for the density of seawater (Sharqawy et al., 2010), assuming a constant temperature of $18{ }^{\circ} \mathrm{C}$ and a constant pressure of $0.1 \mathrm{MPa}(\sim 1$ atm). The calculations of density were conducted using the MATLAB code downloaded from The Seawater Thermophysical Properties Library (http://web.mit.edu/seawater/), which is valid for a temperature range of $0-120^{\circ} \mathrm{C}$, a salinity range of $0-120 \mathrm{ppt}$, and a pressure range of 0 $12 \mathrm{MPa}$. The maximum salinity used in the present experiments was $\sim 49.5 \mathrm{ppt}$, which is covered by the salinity range of the library.

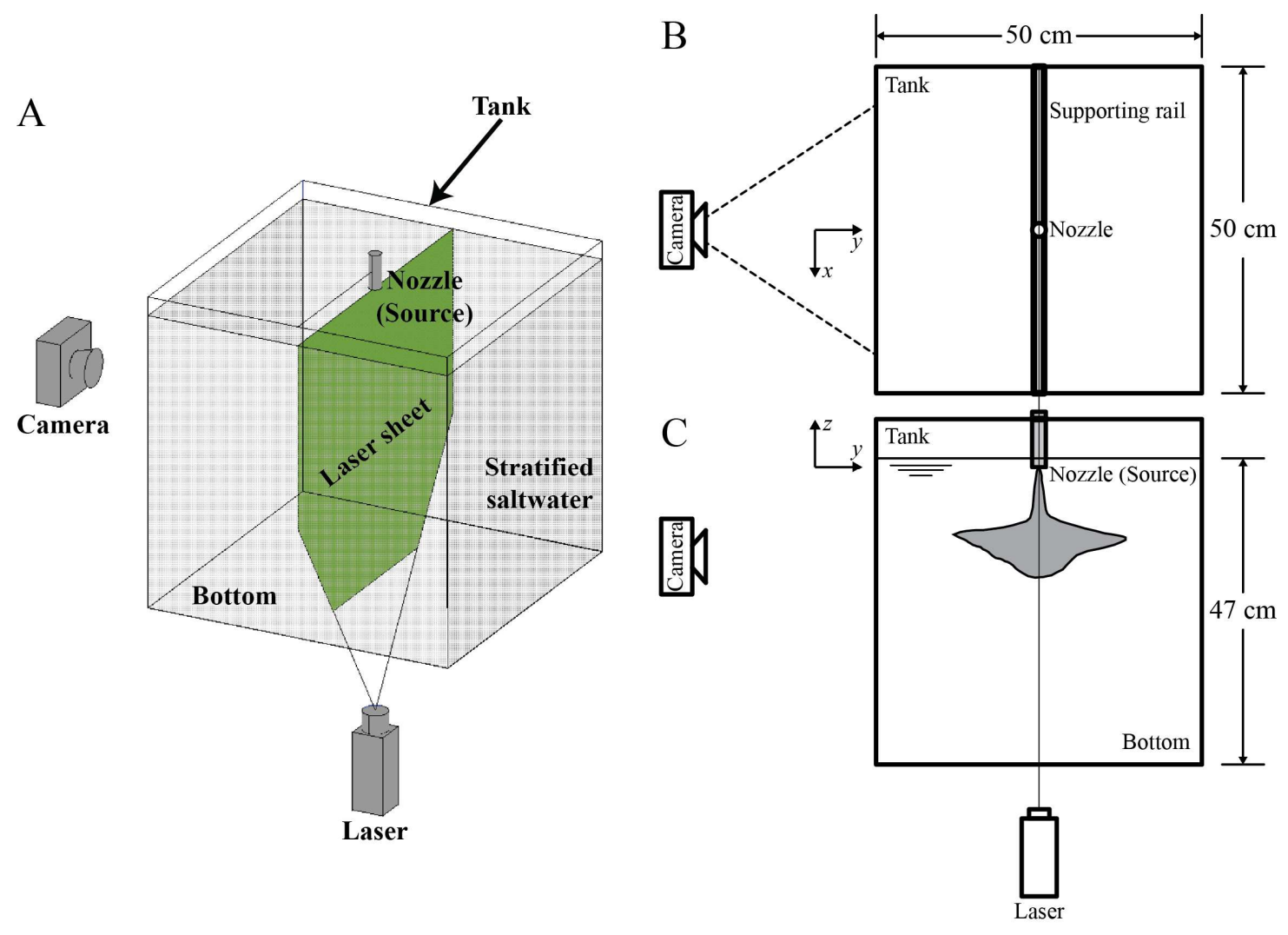

Fig. 1. Experimental setup. (A) Schematic diagram, (B) top view, and (C) side view.

For the PIV setup, a CW (continuous wave) Nd:YAG laser (wave length $532 \mathrm{~nm}, 10 \mathrm{~W}$ ) was used to generate a thin light-sheet of $\sim 3 \mathrm{~mm}$ thickness via light-sheet optics. The light sheet 
was vertically aligned and positioned to pass along the plume axis (Fig. 1). A CMOS camera (Allied Vision Bonito CL-400B $200 \mathrm{fps}$ ) was mounted with a $16 \mathrm{~mm}$ F2.0 lens (AZURE$1620 \mathrm{MX} 5 \mathrm{M}$ ) to achieve a field of view of $\sim 25 \times 20 \mathrm{~cm}$ in the vertical, $x$-z plane (Fig. 1). The camera was set to acquire $2320 \times 1726$ pixel resolution, 8-bit grayscale digital images at 193 frames per second (fps) using an exposure time $\sim 3000 \mu$ s. For PIV, the fluid was seeded with 15 $\mu \mathrm{m}$ diameter polyamide spheres. As to seeding particle concentration, the two tanks in the twotank system for setting up stratification were added seeding particles each at $100 \mathrm{~L}$ fluid per $3 \mathrm{~g}$ particles, and the tank holding the source fluid was added seeding particles at $20 \mathrm{~L}$ fluid per $0.6 \mathrm{~g}$ particles.

Velocity fields were calculated with DaVis (LaVision, Germany), a digital particle image velocimetry (Adrian, 1991; Willert and Gharib, 1991) software package, using cross-correlation of two consecutive frames in the recorded time series of single images (i.e., the 'single frame' mode). A multi-pass iteration algorithm was used with initial and final interrogation window sizes of $64 \times 64$ pixels and $32 \times 32$ pixels $(4.2 \times 4.2 \mathrm{~mm})$, respectively, with an overlap of $50 \%$. Before the cross-correlation velocity calculation, particle intensity normalization was performed to mitigate the slightly varying background illumination intensity. Flow velocity data were exported from DaVis, and postprocessing was conducted using MATLAB (The MathWorks, Natick, MA).

A total of 11 cases, differing in ambient buoyancy frequency and source buoyancy flux, were carried out (Table 1). The ambient buoyancy frequency was calculated as

$$
N=\sqrt{-\frac{g}{\rho_{\text {bottom }}} \frac{\partial \rho}{\partial z}}
$$

where $g$ was gravitational acceleration and $\rho_{\text {bottom }}$ was the fluid density at the bottom of the tank; the vertical density gradient $\left(\frac{\partial \rho}{\partial z}\right)$ was calculated via linear regression of measured density data at different depths, with the coefficient of determination $R^{2}>0.99$ achieved for all cases. While the fluid density at the top of the tank $\left(\rho_{t o p}\right)$ did not vary much among the 11 cases, the difference between $\rho_{\text {bottom }}$ and $\rho_{\text {top }}$ varied from $1.3 \%$ to $3.5 \%$. The resulting ambient buoyancy frequency $(N)$ ranged $0.55-0.99 \mathrm{~s}^{-1}$ (Table 1 ), which was close to the range used in previous tank experiments (e.g., Helfrich and Battisti, 1991).

The source buoyancy flux was calculated as 


$$
B=g \frac{\rho_{\text {source }}-\rho_{\text {top }}}{\rho_{\text {top }}} Q
$$

where $\rho_{\text {source }}$ was the density of source fluid issued from the nozzle, $\rho_{\text {top }}$ was the density of the fluid that surrounded the nozzle at the top of the stratified water column, and $Q$ was source volume flux. The difference between $\rho_{\text {source }}$ and $\rho_{\text {top }}$ varied from $0.5 \%$ to $2.7 \%$, while $Q$ varied from $1.15 \times 10^{-6}$ to $3.90 \times 10^{-6} \mathrm{~m}^{3} \mathrm{~s}^{-1}$. The combined effects caused almost a 5 -fold variation in $B$ (Table 1).

Table 1. Summary of the experiments.

\begin{tabular}{|c|c|c|c|c|c|c|c|c|c|c|c|c|}
\hline Exp. & $\begin{array}{c}D \\
(\mathrm{~mm})\end{array}$ & $\begin{array}{c}N \\
\left(\mathrm{~s}^{-1}\right)\end{array}$ & $\begin{array}{c}\rho_{\text {source }} \\
\left(\mathrm{kg} \mathrm{m}^{-3}\right)\end{array}$ & $\begin{array}{c}\rho_{\text {top }} \\
\left(\mathrm{kg} \mathrm{m}^{-3}\right)\end{array}$ & $\begin{array}{c}\rho_{\text {bottom }} \\
\left(\mathrm{kg} \mathrm{m}^{-3}\right)\end{array}$ & $\begin{array}{c}Q \\
\left(\mathrm{~m}^{3} \mathrm{~s}^{-1}\right)\end{array}$ & $\begin{array}{c}B \\
\left(\mathrm{~m}^{4} \mathrm{~s}^{-3}\right)\end{array}$ & $R_{f}$ & $\begin{array}{l}L_{M} \\
\text { (m) }\end{array}$ & $\begin{array}{l}Z_{\max } \\
(\mathrm{m})\end{array}$ & $\begin{array}{l}v_{t, 1, \max } \\
\left(\mathrm{m}^{2} \mathrm{~s}^{-1}\right)\end{array}$ & $\begin{array}{c}v_{t, 2, \max } \\
\left(\mathrm{m}^{2} \mathrm{~s}^{-1}\right)\end{array}$ \\
\hline 1 & 5 & 0.66 & 1005.8 & 999.4 & 1018.8 & $3.25 \times 10^{-6}$ & $2.03 \times 10^{-7}$ & 0.10 & 0.044 & 0.109 & $2.06 \times 10^{-5}$ & $1.97 \times 10^{-5}$ \\
\hline 2 & 5 & 0.87 & 1005.8 & 1000.5 & 1034.9 & $3.30 \times 10^{-6}$ & $1.71 \times 10^{-7}$ & 0.09 & 0.049 & 0.078 & $1.10 \times 10^{-5}$ & $1.09 \times 10^{-5}$ \\
\hline 3 & 5 & 0.63 & 1011.1 & 999.5 & 1018.7 & $3.30 \times 10^{-6}$ & $3.76 \times 10^{-7}$ & 0.13 & 0.033 & 0.133 & $3.13 \times 10^{-5}$ & $3.21 \times 10^{-5}$ \\
\hline 4 & 5 & 0.55 & 1018.7 & 1001.0 & 1013.6 & $3.90 \times 10^{-6}$ & $6.75 \times 10^{-7}$ & 0.14 & 0.032 & 0.160 & $2.58 \times 10^{-5}$ & $2.63 \times 10^{-5}$ \\
\hline 5 & 7 & 0.57 & 1018.7 & 1000.3 & 1014.4 & $2.55 \times 10^{-6}$ & $4.60 \times 10^{-7}$ & 0.50 & 0.012 & 0.131 & $4.38 \times 10^{-5}$ & $4.02 \times 10^{-5}$ \\
\hline 6 & 5 & 0.88 & 1018.7 & 1000.4 & 1033.5 & $3.09 \times 10^{-6}$ & $5.55 \times 10^{-7}$ & 0.18 & 0.025 & 0.094 & $1.50 \times 10^{-5}$ & $1.43 \times 10^{-5}$ \\
\hline 7 & 7 & 0.65 & 1026.3 & 1001.8 & 1019.2 & $1.15 \times 10^{-6}$ & $2.76 \times 10^{-7}$ & 1.29 & 0.048 & 0.118 & $1.21 \times 10^{-5}$ & $1.16 \times 10^{-5}$ \\
\hline 8 & 5 & 0.65 & 1026.3 & 999.4 & 1019.0 & $3.08 \times 10^{-6}$ & $8.11 \times 10^{-7}$ & 0.22 & 0.020 & 0.147 & $3.88 \times 10^{-5}$ & $3.76 \times 10^{-5}$ \\
\hline 9 & 5 & 0.82 & 1026.3 & 1002.4 & 1030.6 & $3.43 \times 10^{-6}$ & $8.01 \times 10^{-7}$ & 0.18 & 0.024 & 0.125 & $3.50 \times 10^{-5}$ & $3.40 \times 10^{-5}$ \\
\hline 10 & 7 & 0.88 & 1026.3 & 1000.5 & 1034.7 & $3.23 \times 10^{-6}$ & $8.17 \times 10^{-7}$ & 0.47 & 0.013 & 0.099 & $2.36 \times 10^{-5}$ & $2.31 \times 10^{-5}$ \\
\hline 11 & 5 & 0.90 & 1026.3 & 1001.1 & 1036.6 & $3.26 \times 10^{-6}$ & $8.04 \times 10^{-7}$ & 0.20 & 0.022 & 0.118 & $2.48 \times 10^{-5}$ & $2.38 \times 10^{-5}$ \\
\hline
\end{tabular}

$D$ : Nozzle diameter;

$N$ : Ambient buoyancy frequency;

$\rho_{\text {source}}$ : Density of source fluid issued from the nozzle;

$\rho_{\text {top }}$ : Density of the fluid that surrounds the nozzle at the top of the stratified water column;

$\rho_{\text {bottom: }}$ Density of the fluid at the bottom of the tank;

$Q$ : Source volume flux issued from the nozzle;

$B$ : Source buoyancy flux issued from the nozzle;

$R_{f}$. Flux Richardson number [Eq. (4)];

$L_{M}$ : Length scale describing the relative importance of momentum and buoyancy fluxes [Eq. (5)];

$Z_{\max }$ : Maximum plume penetration;

$v_{t, 1, \max }$ : Maximum turbulent viscosity obtained according to Eqs. (11a) and (12);

$v_{t, 2, \text { max }}$ : Maximum turbulent viscosity obtained according to Eqs. (11b) and (12).

The near-source behavior of the plume in each case can be characterized by calculating the flux Richardson number $\left(R_{f}\right)$ defined as (List, 1982; McDuff, 1995)

$$
R_{f}=Q B^{1 / 2} / M^{5 / 4}
$$

where $M=Q^{2} /\left(\pi / 4 D^{2}\right)$ is specific momentum flux of the source. $R_{f}$ characterizes the relative contribution from buoyancy and momentum to the behavior at the source. In the present 11 cases, $R_{f}$ ranged from 0.09 to 1.29 (Table 1), indicating either a forced-plume or plume behavior 
at the source. To put this range in context, a seafloor hydrothermal plume (a black smoker) has been reported to have an $R_{f}$ of 0.3 (McDuff, 1995). A forced-plume will tend to the behavior of a pure plume beyond a characteristic length scale defined as

$$
L_{M}=M^{3 / 4} / B^{1 / 2}
$$

which describes the relative importance of momentum and buoyancy fluxes (Fischer et al., 1979). Taking Case 5 as an example, the flow became a fully plume-like behavior $\sim 1.7$ source diameter downstream from the source (Table 1).

For each case, video recording was made for a duration of $\sim 5 t^{*}$ starting from the onset of the plume, where $t^{*}$ was buoyancy time scale defined as $t^{*}=2 \pi / N$. For all 11 cases considered, $5 t^{*}$ were short ( $35-58$ seconds); it was thus necessary to use high-speed recording (e.g., 193 fps in the present study) to fully resolve the plume development. Since the plume would reach statistically steady state after one or two $t^{*}$ 's (Jiang and Breier, 2014), the instantaneous plume flow velocity data in the time range of $3 t^{*} \leqslant t \leqslant 5 t^{*}$ were used to calculate the mean plume velocity field:

$$
\begin{aligned}
& U(x, z)=\langle u(x, z, t)\rangle \\
& W(x, z)=\langle w(x, z, t)\rangle,
\end{aligned}
$$

where $U$ and $W$ were horizontal and vertical components of the mean plume velocity field, $u$ and $w$ were horizontal and vertical components of the instantaneous plume velocity field obtained from the PIV analysis, and $\langle\cdot\rangle$ denoted time averaging at each field point.

\subsection{Methods for calculating maximum plume penetration and entrainment coefficient}

The maximum plume penetration $\left(Z_{\max }\right)$ was determined from $W(x, z)$ as the depth where the mean plume centerline vertical velocity initially reached zero. By following the entrainment hypothesis (Morton et al., 1956; Turner, 1986), the entrainment coefficient was determined by fitting $W\left(x, z_{i}\right)$, i.e. the mean vertical velocity profile at a given depth $z_{i}$, to the Gaussian profile

$$
W_{G}(x)=W_{m} e^{-\left(x-x_{m}\right)^{2} / b_{i}^{2}}
$$

where $W_{m}$ was the vertical velocity located at $\left(x_{m}, z_{i}\right)$ where the magnitude of the vertical velocity reached its maximum at depth $z_{i}$, and $b_{i}$ was the $e$-folding plume radius at depth $z_{i}$. This fitting calculation was done for all depths to determine $b$ as a tabulated function of $z$. Since the plume 
radius $b$ spread approximately linearly with depth $z$ along the plume stem as $b=-c z$, the expansion rate $c$ was calculated via linear regression between $b$ and $z$. Then, the "top-hat" entrainment coefficient $\left(\alpha_{e}\right)$ was determined from the following equation (Morton et al., 1956; Turner, 1986):

$$
\alpha_{e}=\frac{5}{6} \sqrt{2} c
$$

\subsection{Methods for calculating turbulence properties}

The horizontal $\left(u^{\prime}\right)$ and vertical $\left(w^{\prime}\right)$ components of turbulent velocity fluctuation were calculated as

$$
\begin{aligned}
& u^{\prime}(x, z, t)=u(x, z, t)-U(x, z) \\
& w^{\prime}(x, z, t)=w(x, z, t)-W(x, z) .
\end{aligned}
$$

From time series of $u^{\prime}$ and $w^{\prime}$ fields, turbulent kinetic energy $(k)$ was calculated as

$$
k=\frac{1}{2}\left\langle 2 u^{\prime 2}+w^{\prime 2}\right\rangle
$$

With the assumption of local isotropy, turbulence dissipation rate $(\varepsilon)$ was estimated by using two different formulae: (i) that of Tanaka and Eaton (2007),

$$
\varepsilon_{1}=3 v\left\langle\left(\frac{\partial u^{\prime}}{\partial x}\right)^{2}+\left(\frac{\partial w^{\prime}}{\partial z}\right)^{2}+\left(\frac{\partial u^{\prime}}{\partial z}\right)^{2}+\left(\frac{\partial w^{\prime}}{\partial x}\right)^{2}+2\left(\frac{\partial u^{\prime}}{\partial z} \frac{\partial w^{\prime}}{\partial x}\right)\right\rangle
$$

and (ii) that of $\mathrm{Xu}$ and Chen (2013),

$\varepsilon_{2}=v\left\langle 4\left(\frac{\partial u^{\prime}}{\partial x}\right)^{2}+4\left(\frac{\partial w^{\prime}}{\partial z}\right)^{2}+3\left(\frac{\partial u^{\prime}}{\partial z}\right)^{2}+3\left(\frac{\partial w^{\prime}}{\partial x}\right)^{2}+4\left(\frac{\partial u^{\prime}}{\partial x} \frac{\partial w^{\prime}}{\partial z}\right)+6\left(\frac{\partial u^{\prime}}{\partial z} \frac{\partial w^{\prime}}{\partial x}\right)\right\rangle$,

where $v$ was fluid kinematic viscosity. Based on the two $\varepsilon$ results, two sets of turbulent viscosity $\left(v_{t}\right)$ were calculated as

$$
v_{t, j}=C_{\mu} \frac{k^{2}}{\varepsilon_{j}} \quad(j=1 \text { and } 2)
$$

where $C_{\mu}$ was an empirical constant $\sim 0.09$ (Launder and Spalding, 1972).

\subsection{Method for assessing local isotropy}

Eqs. (11a) and (11b) were derived using the assumption of local isotropy. The validity of the assumption can be assessed by calculating $\left\langle u^{\prime} u^{\prime}\right\rangle,\left\langle w^{\prime} w^{\prime}\right\rangle$, and $\left\langle u^{\prime} w^{\prime}\right\rangle$; if $\left\langle u^{\prime} u^{\prime}\right\rangle \sim\left\langle w^{\prime} w^{\prime}\right\rangle$ and 
$\left\langle u^{\prime} w^{\prime}\right\rangle \sim 0$, then the assumption is valid (Pope, 2000; Webster et al., 2004). $\left\langle u^{\prime} u^{\prime}\right\rangle \sim\left\langle w^{\prime} w^{\prime}\right\rangle$ is equivalent to $\frac{u_{r m s}^{\prime}}{w_{r m s}^{\prime}} \sim 1$, where $u_{r m s}^{\prime}$ and $w_{r m s}^{\prime}$ are the horizontal and vertical root-mean-square velocities of the turbulent fluctuation, and $\left\langle u^{\prime} w^{\prime}\right\rangle \sim 0$ is equivalent to $\frac{\left\langle u^{\prime} w^{\prime}\right\rangle}{k} \sim 0$. Thus, $\frac{u_{r m s}^{\prime}}{w_{r m s}^{\prime}}$ and $\frac{\left\langle u^{\prime} w^{\prime}\right\rangle}{k}$ were calculated to assess the assumption of local isotropy.

\subsection{Method for calculating spatial turbulent energy spectra}

To further assess the isotropy of plume turbulence, one-dimensional (1D) energy spectra were calculated along the vertical direction (Bertuccioli et al., 1999; Doron et al., 2001):

$$
E_{i i}\left(\kappa_{3}\right)=\frac{L}{2 \pi n^{2}} \sum F_{i}\left(\kappa_{3}\right) F_{i}^{*}\left(\kappa_{3}\right),
$$

where $\kappa_{3}$ was the wavenumber in the vertical direction, $L$ was the domain length, $n$ was the number of points, $F_{i}$ denoted the Fourier transform of the horizontal component $\left(u^{\prime}\right.$, when $\left.i=1\right)$ or the vertical component $\left(w^{\prime}\right.$, when $\left.i=3\right)$ of the turbulent velocity fluctuation along the plume centerline, and $F_{i}{ }^{*}$ was the complex conjugate of $F_{i}$. Subsequently, the mean 1D energy spectra were obtained by time averaging the instantaneous spectra over the time range of $3 t^{*} \leqslant t \leqslant 5 t^{*}$.

\subsection{Assessment of errors due to variations of index of refraction within the stratified fluid}

In stratified fluid, the index of refraction varies with the local value of the fluid density, thereby causing blurring of images of individual particles as well as the associated errors in the PIV measurement. One way to mitigate this problem is to match the index of refraction throughout the stratified fluid column (Alahyari and Longmire, 1994; Daviero et al., 2001; Horner-Devine, 2006). However, the present study did not take any measure to match the index of refraction in the fluid. Therefore, it was necessary to conduct a follow-up experiment to assess errors due to variations of index of refraction within the stratified fluid. For this purpose, 11 point markers were painted white and separated one by one $\sim 8 \mathrm{~mm}$ along a rigid, thin rod that was otherwise painted black. The rod that carried the 11 fixed points was placed horizontally in the upper middle of the tank where the plume cap region was usually located. Then, a plume experiment was conducted with stratification and source conditions similar to Case 5 (Table 1) but without the PIV seeding particles added. The apparent motion of these fixed particles were video- 
recorded using the same laser illumination and video frame rate as in the previous PIV measurement. ImageJ software was used to retrieve time series of apparent positions of each particle and then velocity components of the apparent motion calculated using finite difference. The particle that was located closest to the plume centerline appeared to display the strongest apparent motion, but the apparent motion's velocity components were at most a few $\mathrm{mm} \mathrm{s}^{-1}$ (Fig. 2) with near zero means in the time average $\left(U=8.6 \times 10^{-4} \mathrm{~mm} \mathrm{~s}^{-1}\right.$ and $\left.W=-7.0 \times 10^{-3} \mathrm{~mm} \mathrm{~s}^{-1}\right)$. Thus, the apparent motion due to variations of index of refraction in the fluid will not contribute to the mean plume flow. By using Eq. (10), the 'pseudoturbulent' kinetic energy of the apparent motion of the same particle was calculated to be $8.1 \times 10^{-7} \mathrm{~J} \mathrm{~kg}^{-1}$, which was at most $1-2$ percent of the turbulent kinetic energy of the plume turbulence at the same location (see Fig. 6A below). Thus, the apparent motion due to variations of index of refraction in the fluid will only contribute insignificantly to the plume turbulence.

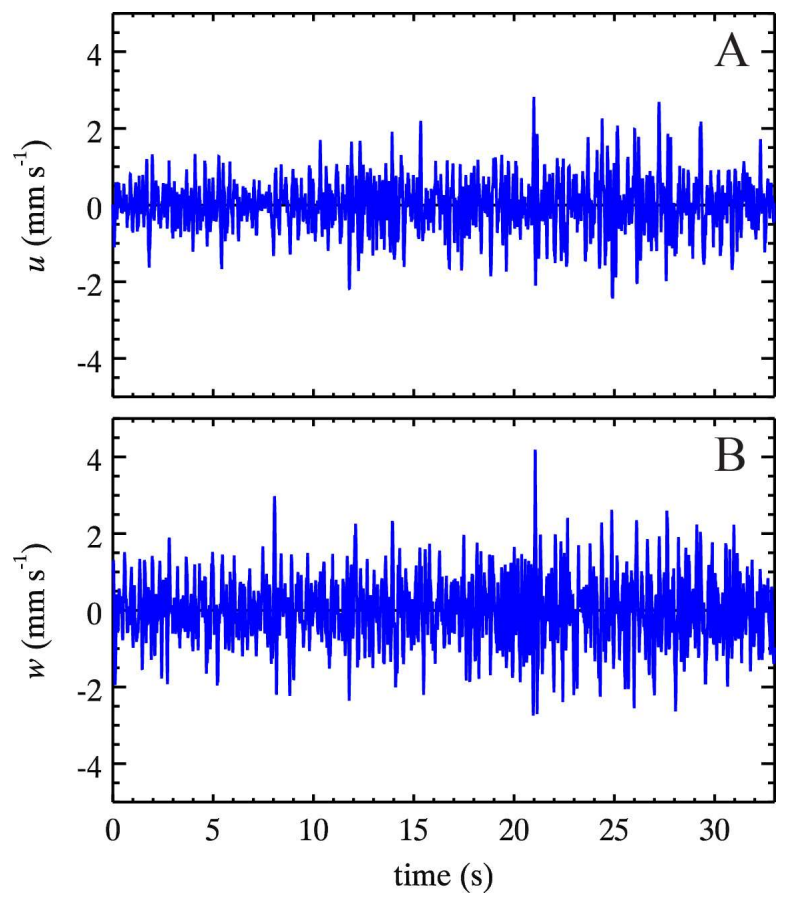

Fig. 2. Measured time series of velocity components of a fixed particle's apparent motion due to variations of index of refraction in a stratified plume flow. (A) The horizontal component $u$, and (B) the vertical component $w$. 


\section{Results}

\subsection{Instantaneous and mean plume characteristics}

The instantaneous plume velocity field is made up of turbulent eddies or vortices at a hierarchy of sizes (Online supplementary material - video of instantaneous plume velocity vector and vorticity fields obtained from time-resolved PIV). Along the plume stem, small turbulent eddies engulf the background fluid into the plume. While descending, these eddies become larger and larger in size and interact rather randomly with each other. Within the plume cap region, turbulent eddies overshoot to reach the outer edge of the plume cap, entrain a substantial amount of fluid from outside the plume cap, and then arise to spread laterally (Note that the plume goes downward in the present study, in contrast to a seafloor hydrothermal plume that rises up).

The mean plume velocity field shows a persistent entrainment region along the plume stem, characterized by nearly horizontal inward-flow at the edge (Fig. 3A, C). This well-known entrainment is termed here as the 'plume-stem' entrainment. Down below the plume stem, the flow is dominated by lateral spreading. However, above and below this strong lateral spreading flow there are two branches of relatively weak inward-flow. Within the plume cap region and lateral to the plume core, there is strong recirculation formed by (i) the downward flow of the plume core, (ii) the lateral spreading flow emanating from the plume cap region, and (iii) the entrained inward-flow above the lateral spreading flow. Also evidenced is a persistent entrainment region along the outer edge of the plume cap, where fluid is entrained into the plume cap from outside (Fig. 3A, C). This less well-known entrainment is termed here as the 'plumecap' entrainment. The mean plume vorticity field shows features consistent with the velocity field (Fig. 3A). In particular, shear instabilities are evidenced by both curvatures in the vorticity field and eddies in the velocity field along the boundaries between the lateral spreading flow and the two branches of inward-flow. The mean vertical velocities of the plume core fit well to the Gaussian profile [Eq. (7)], with an averaged expansion rate $\sim 0.124$ (Fig. 3B, see also Table 2 below). Based on all above observations, a schematic of a turbulent buoyant plume has been constructed to describe the regions of 'plume-stem' entrainment, 'plume-cap' entrainment, and lateral spreading, and to illustrate the phenomenon that turbulent eddy size increases with depth inside the plume (Fig. 3D). 
A

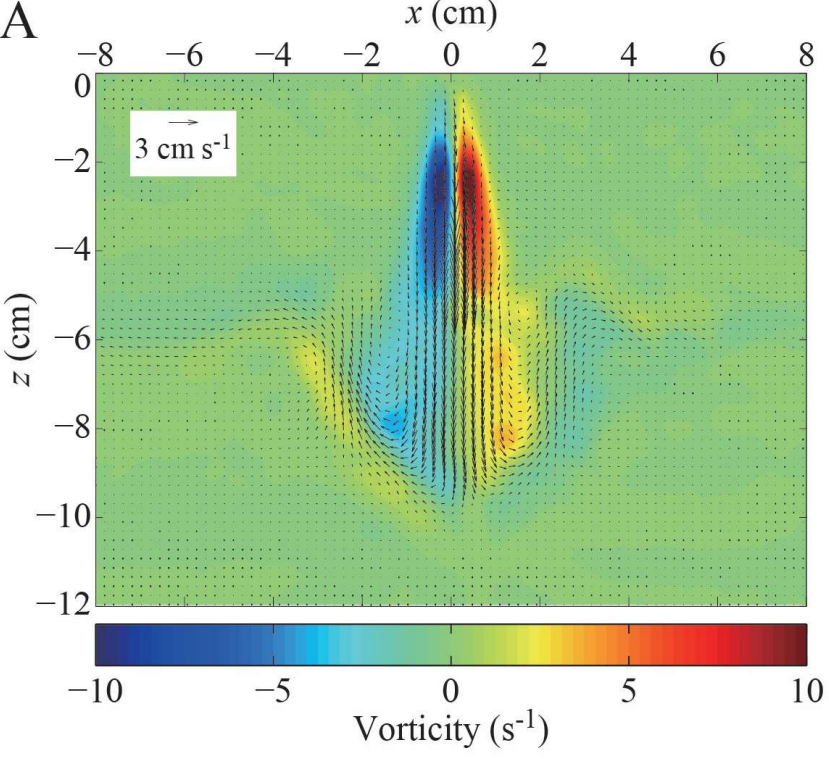

B

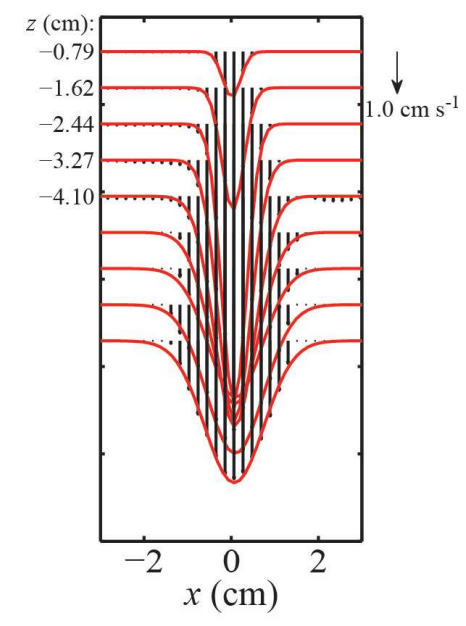

D

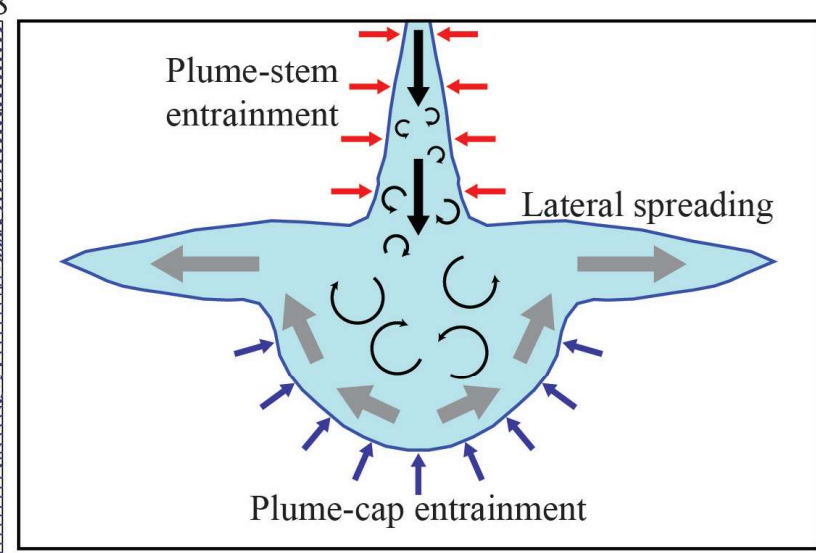

C

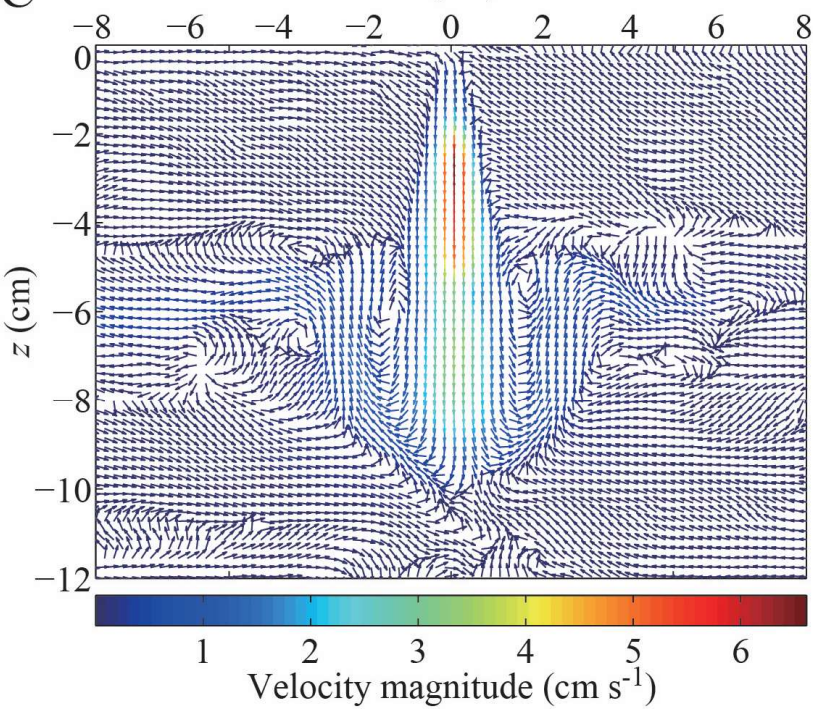




\subsection{Scaling for maximum plume penetration}

The scaling for maximum plume penetration has been previously given as

$$
Z_{\text {max }}=C\left(B / N^{3}\right)^{1 / 4},
$$

where $C=3.76$, a scaling coefficient determined for a point-source plume in a stratified fluid (Morton et al., 1956; Briggs, 1969). Linear regression of the present experimental data has confirmed this scaling but with a slightly smaller scaling coefficient (i.e., $C=3.56$, Fig. 4). The minor discrepancy is likely due to the fact that the present small-scale experiments used a finitesized source that might be too big to approximate a point source.

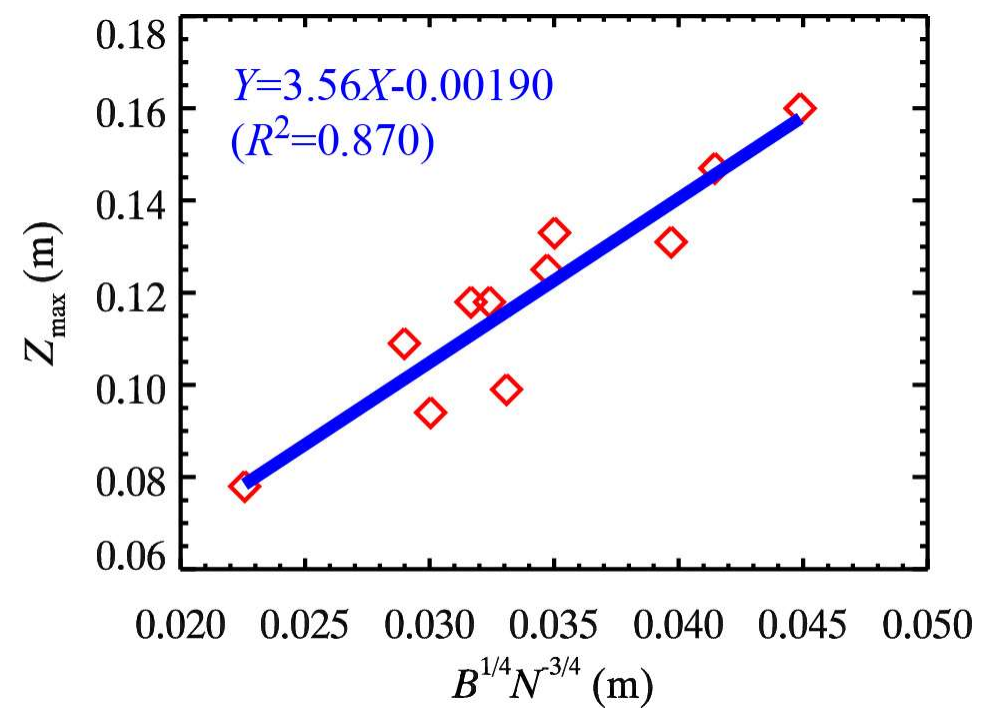

Fig. 4. Scaling for maximum plume penetration, $Z_{\max }$, with source buoyancy flux, $B$, and buoyancy frequency, $N$.

\subsection{Entrainment coefficient}

Linear regression between the Gaussian-fitted plume radius $b$ and depth $z$ is excellent (Fig. 5), achieving high coefficients of determination $R^{2}$ for all cases $[0.989 \pm 0.014$ (Mean $\pm \mathrm{SD}$ )]. The resulting expansion rate $c$ is $0.122 \pm 0.005$ (Mean $\pm \mathrm{SD}$, Table 2), while the 'top-hat' entrainment coefficient $\alpha_{e}$ is $0.143 \pm 0.006$ (Mean $\pm \mathrm{SD}$, Table 2).

According to the theory based on the entrainment hypothesis (Morton et al., 1956; Turner, 1986), the 'top-hat' entrainment coefficient $\alpha_{e}$ is related to the scaling for maximum plume penetration by 


$$
Z_{\max }=1.36 / \alpha_{e}^{1 / 2}\left(B / N^{3}\right)^{1 / 4} .
$$

If the mean entrainment coefficient, 0.143 , is substituted into Eq. (15), a scaling coefficient of $C$ $=3.60$ will be obtained for the maximum plume penetration scaling [i.e., Eq. (14)], which is close to $C=3.56$ that has been obtained directly from linear regression of the experimental data (Fig. 4). Thus, the present laboratory experimental results of the scaling for maximum plume penetration and entrainment coefficient are consistent with the previous theory based on the entrainment hypothesis.

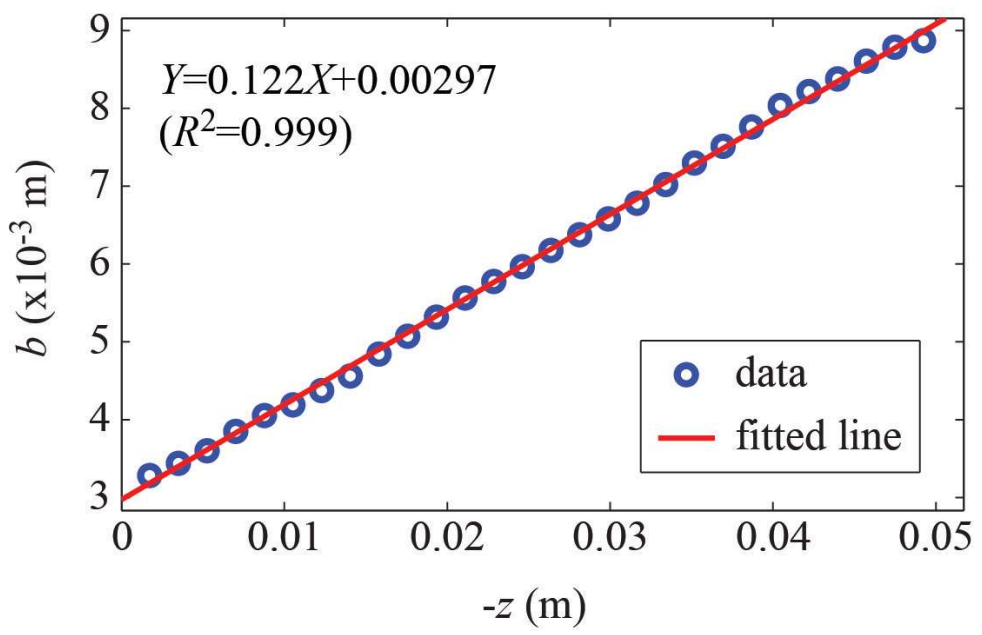

Fig. 5. Linear regression between the Gaussian-fitted plume radius $b$ and depth $z$ for Case 1 .

Table 2. Results of expansion rate and entrainment coefficient

\begin{tabular}{ccc}
\hline Case & $\begin{array}{c}\text { Expansion rate of } \\
\text { mean vertical velocity } \\
c\end{array}$ & $\begin{array}{c}\text { 'Top-hat' entrainment } \\
\text { coefficient } \\
\alpha_{\boldsymbol{e}}\end{array}$ \\
\hline 1 & 0.122 & 0.144 \\
2 & 0.125 & 0.147 \\
3 & 0.121 & 0.143 \\
4 & 0.112 & 0.132 \\
5 & 0.124 & 0.146 \\
6 & 0.122 & 0.144 \\
7 & 0.131 & 0.154 \\
8 & 0.125 & 0.147 \\
9 & 0.123 & 0.145 \\
10 & 0.117 & 0.138 \\
11 & 0.116 & 0.137 \\
\hline Mean $\pm \mathrm{SD}$ & $0.122 \pm 0.005$ & $0.143 \pm 0.006$ \\
\hline
\end{tabular}




\subsection{Plume turbulence characteristics}

Measured fields of turbulent kinetic energy ( $k$, Fig. 6A), turbulence dissipation rate ( $\varepsilon$, Fig. 6B), and turbulent viscosity ( $v_{t}$, Fig. 6C) all display an upside-down mushroom-like spatial distribution (Note that the plume goes downward in the present study, in contrast to a seafloor hydrothermal plume that rises up). The ranges of variation for $k, \varepsilon$, and $v_{t}$ all cover at least three orders of magnitude. Elevated values of both $k$ and $\varepsilon$ are confined mainly within the plume stem region. By contrast, maximums of $v_{t}$ occur within the plume cap region. To our knowledge, it is the first time that these patterns for buoyant plume turbulence in stratified fluids have ever been viewed experimentally. Plumes in non-stratified fluids do not display these patterns (e.g., Pham et al., 2005; Watanabe et al., 2005; Grafsrønningen et al., 2011; Diez et al., 2005). 


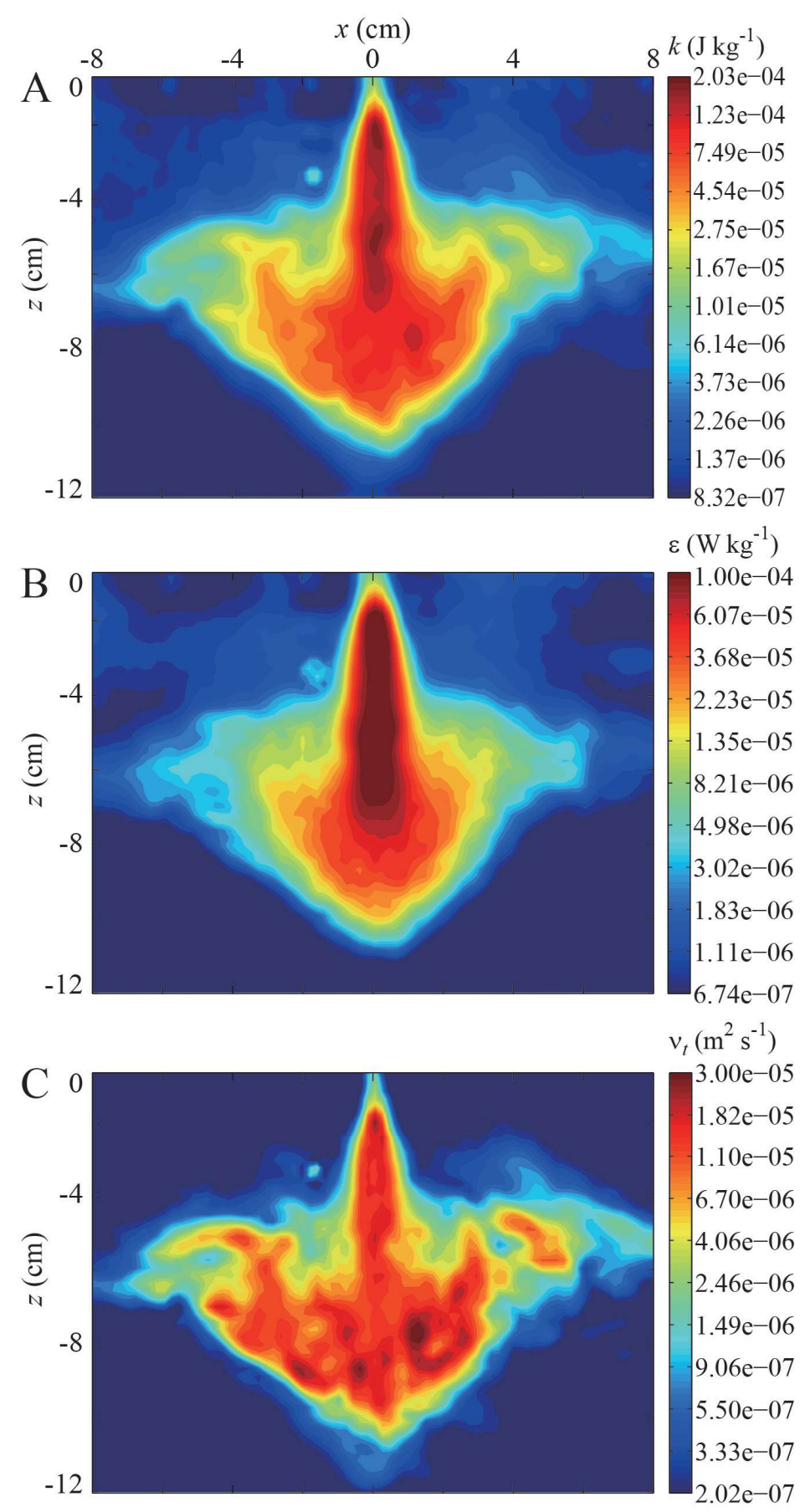

Fig. 6. Characteristics of the plume turbulence (Case 5). PIV measured fields of (A) turbulent kinetic energy, $k$, (B) turbulence dissipation rate, $\varepsilon$, and (C) turbulent viscosity, $v_{t}$. Eq. (11b) was used to calculate $\varepsilon$ and $v_{t}$. 


\subsection{Scaling for maximum turbulent viscosity}

Both Eq. (11a) and Eq. (11b) have resulted in similar values of $\varepsilon$ and hence similar values of $v_{t}$ (Table 1). Therefore, only maximum values of $v_{t}$ obtained by using Eq. (11b) (i.e., $v_{t, 2, \max }$ of Table 1) have been used to determine the scaling for maximum turbulent viscosity via linear regression (Fig. 7):

$$
v_{t, \max }=0.030(B / N)^{1 / 2} .
$$

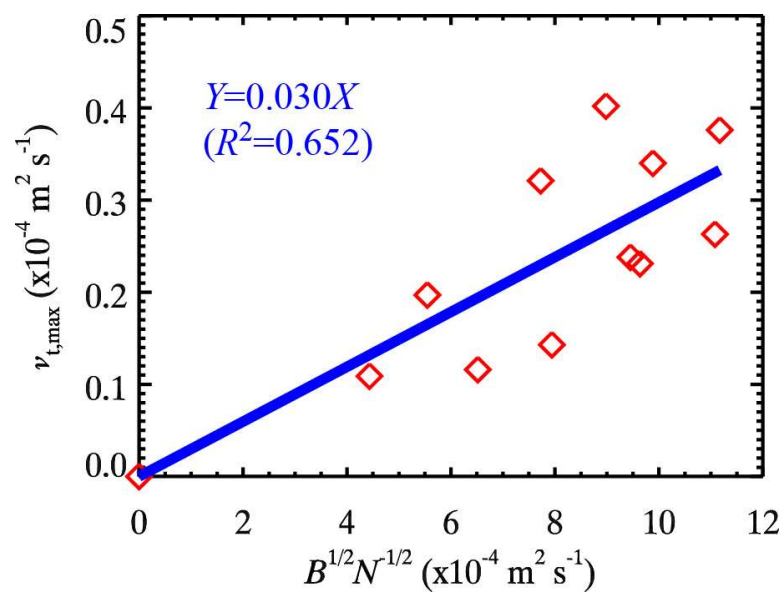

Fig. 7. Scaling for maximum turbulent viscosity, $v_{t, \max }$, with source buoyancy flux, $B$, and buoyancy frequency, $N$. The linear correlation is significant at $p<0.01$ (Pearson's correlation, $R$ $=0.81, n=11, p=0.0025)$.

\subsection{Assessment of local isotropy}

Ten small areas were chosen, in which $\frac{u_{r m s}^{\prime}}{w_{r m s}^{\prime}}$ and $\frac{\left\langle u^{\prime} w^{\prime}\right\rangle}{k}$ were calculated at every field point (Fig. 8) and were spatially averaged within each selected area (Table 3). These areas covered sites in the plume source region (Area 1), plume stem region (Area 2), plume cap region (Area 3), maximum penetration region (Area 4), and plume lateral edges (Areas 5-10).

Values of spatially averaged $\frac{u_{r m s}^{\prime}}{w_{r m s}^{\prime}}$ are larger than 0.70 in most areas except for Area 2 where the plume reaches its maximum vertical velocity and Area 4 where the plume achieves its maximum penetration and turbulence is the weakest. All areas located at the lateral edges of the plume (Areas 5-10) attain values of spatially averaged $\frac{u_{r m s}^{\prime}}{w_{r m s}^{\prime}}$ larger than 0.8 , which are close to 
the ideal value of 1.0 for perfect local isotropy; these areas are characterized by strong entrainment and turbulence. Also, absolute values of spatially averaged $\frac{\left\langle u^{\prime} w^{\prime}\right\rangle}{k}$ are smaller than 0.2 in most areas except for Area 2 and Area 4. A few areas in the plume cap region (Areas 3, 9, and 10) have very small absolute values of spatially averaged $\frac{\left\langle u^{\prime} w^{\prime}\right\rangle}{k}$. All these results suggest that the assumption of local isotropy is valid for these small-scale plumes generated in the laboratory.
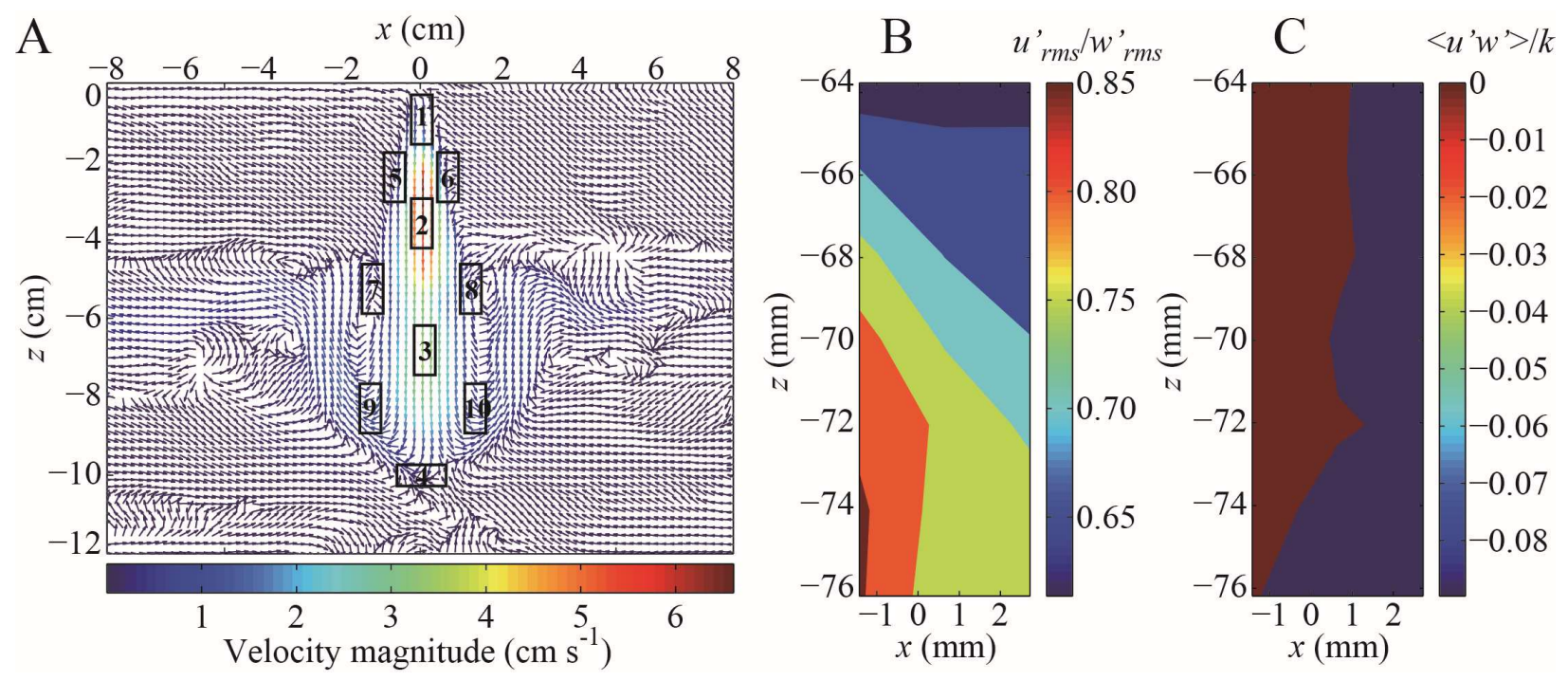

Fig. 8. Assessment of local isotropy (Case 5). (A) Selected areas for assessing local isotropy. (B) Contour plot of $\frac{u_{r m s}^{\prime}}{w_{r m s}^{\prime}}$ for Area 3. (C) Contour plot of $\frac{\left\langle u^{\prime} w^{\prime}\right\rangle}{k}$ for Area 3. Note that other areas also show similar patterns.

Table 3. Summary of local isotropy assessment for Case 5.

\begin{tabular}{ccccc}
\hline Area & $\begin{array}{c}\text { Spatially } \\
\text { averaged } \\
u_{r m s}^{\prime}\end{array}$ & $\begin{array}{c}\text { Spatially } \\
\text { averaged } \\
w_{r m s}^{\prime}\end{array}$ & $\begin{array}{c}\text { Spatially } \\
\text { averaged } \\
\frac{u_{r m s}^{\prime}}{w_{r m s}^{\prime}}\end{array}$ & $\begin{array}{c}\text { Spatially } \\
\text { averaged } \\
\left\langle u^{\prime} w^{\prime}\right\rangle\end{array}$ \\
& $\left(\mathrm{m} \mathrm{s}^{-1}\right)$ & $\left(\mathrm{m} \mathrm{s}^{-1}\right)$ & & \\
\hline $\mathbf{1}$ & $2.80 \times 10^{-3}$ & $4.55 \times 10^{-3}$ & 0.70 & -0.101 \\
$\mathbf{2}$ & $7.79 \times 10^{-3}$ & $1.29 \times 10^{-2}$ & 0.60 & -0.245 \\
$\mathbf{3}$ & $8.08 \times 10^{-3}$ & $1.11 \times 10^{-2}$ & 0.74 & 0.003 \\
$\mathbf{4}$ & $2.52 \times 10^{-3}$ & $4.44 \times 10^{-3}$ & 0.58 & -0.257 \\
$\mathbf{5}$ & $2.24 \times 10^{-3}$ & $2.23 \times 10^{-3}$ & 1.04 & 0.183 \\
$\mathbf{6}$ & $3.57 \times 10^{-3}$ & $4.87 \times 10^{-3}$ & 0.85 & -0.160 \\
$\mathbf{7}$ & $3.84 \times 10^{-3}$ & $4.57 \times 10^{-3}$ & 0.84 & 0.093 \\
$\mathbf{8}$ & $4.58 \times 10^{-3}$ & $5.60 \times 10^{-3}$ & 0.82 & -0.142 \\
$\mathbf{9}$ & $6.17 \times 10^{-3}$ & $7.68 \times 10^{-3}$ & 0.82 & 0.025 \\
$\mathbf{1 0}$ & $7.48 \times 10^{-3}$ & $8.63 \times 10^{-3}$ & 0.89 & -0.021 \\
\hline
\end{tabular}


Non-dimensionalized one-dimensional spatial turbulent energy spectra, $E_{11}\left(\kappa_{3}\right) /\left(\varepsilon v^{5}\right)^{1 / 4}$ and $0.75 E_{33}\left(\kappa_{3}\right) /\left(\varepsilon v^{5}\right)^{1 / 4}$, integrated along the plume centerline are almost equal to each other in the high wavenumber range (the non-dimensional wavenumber $\eta \kappa_{3}>0.15$, Fig. 9), where $\varepsilon$ is turbulence dissipation rate, $v$ is fluid kinematic viscosity, and $\eta=\left(v^{3} / \varepsilon\right)^{1 / 4}$ is the Kolmogorov length scale. Since $E_{11}\left(\kappa_{3}\right) /\left(\varepsilon v^{5}\right)^{1 / 4}$ is equal to $0.75 E_{33}\left(\kappa_{3}\right) /\left(\varepsilon v^{5}\right)^{1 / 4}$ in isotropic turbulence (Pope, 2000; Nimmo Smith et al., 2004), this result indicates good isotropy at dissipation scales. Note that the shape, location, and slope of the present spectra at dissipation scales are consistent with previous measured spectra for various turbulent flow types [see Fig. 6.14 in Pope (2000)]. However, the spectra do not exhibit a sizable range of the $-5 / 3$ slope, indicating that no substantial inertial subrange is present in these small-scale plumes generated in the laboratory. For Case 9 (Table 1), a rough estimate of the Reynolds number based on the maximum mean flow velocity in the plume and the maximum penetration depth is $\sim 8,000$, which is too low to produce turbulence of a substantial inertial subrange (Grant et al., 1962). For real scale submarine hydrothermal plumes that have much larger Reynolds numbers, it can be expected that the spectra should exhibit a sizable range of the $-5 / 3$ slope with the presence of a substantial inertial subrange, similar to what has long been shown for an energetic tidal channel (Grant et al., 1962). 


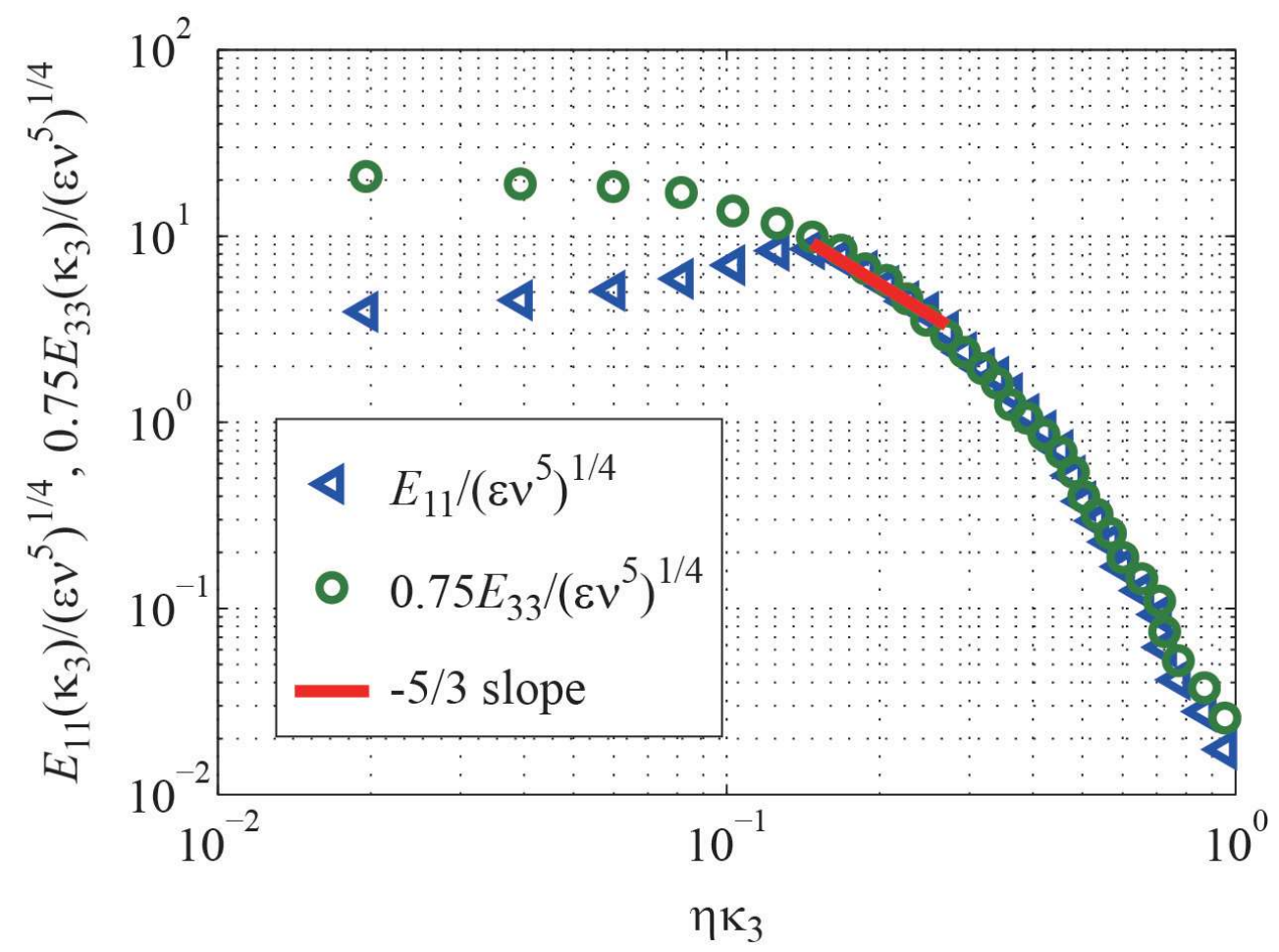

Fig. 9. Non-dimensionalized one-dimensional energy spectra, $E_{11}(\kappa 3) /\left(\varepsilon v^{5}\right)^{1 / 4}$ and $0.75 E_{33}\left(\kappa_{3}\right) /\left(\varepsilon v^{5}\right)^{1 / 4}$, versus the non-dimensional wavenumber $\eta \kappa_{3}$, calculated along the plume centerline for Case 9. $\varepsilon$ is turbulence dissipation rate, $v$ is fluid kinematic viscosity, and $\eta=$ $\left(v^{3} / \varepsilon\right)^{1 / 4}$ is the Kolmogorov length scale.

\section{Discussion}

The present PIV measurement of laboratory-generated buoyant plumes in stratified saltwater is at least qualitatively consistent with the CFD simulation results of real scale hydrothermal plumes (Jiang and Breier, 2014). First, the PIV measured mean plume flow field clearly shows two branches of inward-flow above and below the lateral spreading flow (Fig. 3C), confirming the prediction from the previous CFD simulation study [Fig. 7A of Jiang and Breier (2014)]. The PIV measured plume cap flow field also shows persistent entrainment of fluid along the outer edge of the plume cap (Fig. 3C, D, Online supplementary material - video of instantaneous plume velocity vector and vorticity fields obtained from time-resolved PIV). All these features in the PIV measured flow field of the plume cap overturning region confirm the 'plume-top' or 'plume-cap' entrainment as well as the processes of lateral entrainment and detrainment that has been demonstrated by a previous large-eddy simulation (LES) study of a buoyant plume in a 
stably stratified environment (Devenish et al., 2010a). In that LES study, the plume goes upward. There exists a region with negative vertical velocities at the top of the plume, thereby indicating the 'plume-top' entrainment in the region where the plume is overturning. The 'plume-top' entrainment means that the plume entrains ambient fluid from above the top of the plume. A recent analytical and experimental study by Camassa et al. (2016) has also shown for turbulent buoyant jets impinging on sharp stratification there is extra mixing occurring at the density jump, which may be related to the 'plume-top' entrainment. Ambient lateral currents are likely present near seafloor where hydrothermal plumes occur. Depending on ambient current strength and background stratification level, the currents can affect both the maximum rise height and the entrainment coefficient of a hydrothermal plume to various degrees (Middleton, 1986; Devenish et al., 2010b). However, it has not yet been clear how ambient currents affect the 'plume-top' entrainment.

Early works did not really consider the abovementioned flow characteristics in the plume cap region and neglected the 'plume-cap' entrainment completely, but still suggested a scaling for the volume flux of the final horizontal flow at the spreading level as $Q_{\text {spread }}=C_{Q} B^{3 / 4} N^{-5 / 4}$, where the scaling coefficient $C_{Q}$ was in the range of 1.2 - 1.4 (Morton et al., 1956; Briggs, 1975). Recently, Rooney and Devenish (2014) used the LES data by Devenish et al. (2010a) to improve the scaling as $Q_{\text {spread }}=0.98 B^{3 / 4} N^{-5 / 4}$. Similarly, we used the CFD simulation data by Jiang and Breier (2014) to end up with $Q_{\text {spread }}=1.1\left(B_{\text {asymp }}\right)^{3 / 4} N^{-5 / 4}$, where the so-called asymptotic buoyancy flux $\left(B_{\text {asymp }}\right)$ was used in place of the real source buoyancy flux $(B)$, following the suggestion by Turner and Campbell (1987) to account for the very large variations of compressibility and density and non-linear mixing close to a real deep-sea hydrothermal vent. Moreover, Jiang and Breier (2014) obtained a scaling for the maximum cumulative volume flux that was transported vertically along the plume stem before entering the plume cap region; this scaling is rewritten here in terms of $B_{\text {asymp }}$ as $Q_{\text {stem }}=0.52\left(B_{\text {asymp }}\right)^{3 / 4} N^{-5 / 4}$. Therefore, $Q_{\text {stem }} /$ $Q_{\text {spread }} \sim 0.5$, suggesting that the 'plume-cap' entrainment plays a role at least as important as that of the 'plume-stem' entrainment in contributing to the final volume flux at the plume spreading level.

Second, the present PIV measured buoyant plume turbulence shows that both the turbulent kinetic energy $(k)$ field and the turbulence dissipation rate $(\varepsilon)$ field attain their maximum value close to the source (Fig. 6A, B). By contrast, the measured turbulent viscosity 
$\left(v_{t}\right)$ field reaches its maximum values within the plume cap region (Fig. 6C). These results are consistent with predictions from the previous CFD simulation study of real scale hydrothermal plumes [Fig. 6A-C of Jiang and Breier (2014)]. Also, these results correspond well with the observed phenomenon that the sizes of smoke billows of hydrothermal plumes increase rapidly with height, as having been explained in Jiang and Breier (2014). A ramification of these results is that it might be difficult to use turbulence microstructure measurement within hydrothermal plumes to estimate turbulent diffusivity $\left(K_{\rho}\right)$ from turbulence dissipation measurement, which is based on the relationship $K_{\rho} \leq 0.2 \varepsilon / N^{2}$. Osborn (1980) proposed this relationship by assuming a simple balance between local shear production, dissipation, and loss to buoyancy that was derived from the turbulent kinetic energy equation. For hydrothermal plumes this assumption does not hold, because buoyancy contributes significantly to the production of turbulent kinetic energy, altering the spatial and temporal characteristics of turbulent mixing and diffusivity significantly.

Third, the present PIV measurement suggests a scaling for maximum plume turbulent viscosity, which resides in the plume cap region, as $v_{t, \max }=0.030(B / N)^{1 / 2}$. From their CFD simulations of real scale hydrothermal plumes, Jiang and Breier (2014) obtained a similar scaling for maximum plume turbulent viscosity, which also resides in the plume cap region; this scaling is rewritten here in terms of $B_{\text {asymp }}$ as $v_{t, \max }=0.054\left(B_{\text {asymp }} / N\right)^{1 / 2}$. The true value of the scaling coefficient is more likely in the range of $0.030-0.054$, because the PIV measurement might have underestimated the turbulent viscosity due to coarse spatial resolution while the CFD simulations might have inherently overestimated the turbulent viscosity. For Case 5 (Table 1), the Kolmogorov length scale $\eta$ is estimated to be $\sim 10 \mathrm{~mm}$ based on a turbulence dissipation rate of $1.0 \times 10^{-4} \mathrm{~W} \mathrm{~kg}^{-1}$ (Fig. 6B). The present study uses a PIV spacing $\Delta l \sim 4.2 \mathrm{~mm}$. Thus, $\Delta l / \eta \sim 0.42$ lies in the upper bound of the range to resolve the turbulence dissipation rate (Tanaka and Eaton, 2007). The present 2D PIV measurement has to assume local isotropy in order to use Eq. (11a) or (11b) to calculate turbulence dissipation rate. However, the local isotropy assumption is not exactly valid and only good for up to $\sim 80 \%$, and therefore also brings errors to the analysis.

To summarize, the present PIV measurement shows that a buoyant plume in a stratified fluid generates strengthened turbulence and associated entrainment and mixing activities within the plume cap, which is roughly the region between $z=\sim 0.6 Z_{\max }$ and $Z_{\max }$. Plume turbulence within the plume cap region causes the so-called 'plume-cap' entrainment that plays an equally 
important role as the 'plume-stem' entrainment in supplying the final volume flux at the plume spreading level. Similarly, for a seafloor hydrothermal plume, it can be expected that the 'plumestem' entrainment and the 'plume-top' entrainment should play equal roles in supplying final volume flux at the plume spreading level. As such, the fluid derived from the subseafloor as well as the benthic boundary layer, the seawater entrained along the plume stem, and the seawater entrained from above the plume top should mix together within the plume cap region to produce the neutrally buoyant plume fluid at the spreading level.

\section{Acknowledgements}

WZ gratefully acknowledges the China Scholarship Council for providing a scholarship for him to study at the Woods Hole Oceanographic Institution (WHOI) as a guest student. Part of this work was financially supported by the National Natural Science Foundation of China and Natural Science Foundation of Zhejiang Province under respective Project no. 11672267 and LR16E090001 to ZH. While visiting Ocean College at Zhejiang University, HJ initiated this work and helped constructing the experimental setup; he was supported by a National Science Foundation Grant NSF OCE-1038055 through the RIDGE2000 program and an internal funding from WHOI. The authors thank Mr. Liang Zhao at Zhejiang University for assistance in conducting the experiments. The authors thank five anonymous reviewers for providing very helpful and constructive comments that improved the manuscript.

\section{References}

Adrian, R.J., 1991. Particle-imaging techniques for experimental fluid-mechanics. Annu. Rev. Fluid Mech. 23, 261-304.

Adrian, R.J., Westerweel, J., 2011. Particle Image Velocimetry. Cambridge University Press. Alahyari, A., Longmire, E.K., 1994. Particle image velocimetry in a variable density flow: application to a dynamically evolving microburst. Exp. Fluids 17, 434-440.

Baker, E.T., German, C.R., Elderfield, H., 1995. Hydrothermal plumes over spreading-center axes: global distributions and geological inferences, in: Humphris, S.E., Zierenberg, R.A., Mullineaux, L.S., Thomson, R.E. (Eds.), Seafloor Hydrothermal Systems: Physical, 
Chemical, Biological, and Geological Interactions. Geophysical Monograph 91, American Geophysical Union, pp. 47-71.

Bertuccioli L., Roth, G.I., Katz, J., Osborn, T.R., 1999. A submersible particle image velocimetry system for turbulence measurements in the bottom boundary layer. J. Atmos. Oceanic Technol. 16, 1635-1646.

Briggs, G.A., 1969. Optimum formulas for buoyant plume rise. Phil. Trans. Roy. Soc. Lond. A 265, 197-203.

Briggs, G.A., 1975. Plume rise predictions, in: Haugen, D.A. (Ed.), Lectures on Air Pollution and Environmental Impact Analyses. American Meteorological Society, Oak Ridge, pp. 59111.

Camassa, R., Lin, Z., McLaughlin, R.M., Mertens, K., Tzou, C., Walsh, J., White, B., 2016. Optimal mixing of buoyant jets and plumes in stratified fluids: theory and experiments. J. Fluid Mech. 790, 71-103.

Carazzo, G., Jellinek, A.M., Turchyn, A.V., 2013. The remarkable longevity of submarine plumes: implications for the hydrothermal input of iron to the deep-ocean. Earth Planet. Sci. Lett. 382, 66-76.

Contini, D., Donateo, A., Cesari, D., Robins, A.G., 2011. Comparison of plume rise models against water tank experimental data for neutral and stable crossflows. J. Wind Eng. Ind. Aerodyn. 99, 539-553.

Crone, T.J., McDuff, R.E., Wilcock, W.S.D., 2008. Optical plume velocimetry: a new flow measurement technique for use in seafloor hydrothermal systems. Exp. Fluids 45, 899-915.

Daviero, G.J., Roberts, P.J.W., Maile, K., 2001. Refractive index matching in large-scale stratified experiments. Exp. Fluids 31, 119-126.

Devenish, B.J., Rooney, G.G., Thomson, D.J., 2010a. Large-eddy simulation of a buoyant plume in uniform and stably stratified environments. J. Fluid Mech. 652, 75-103.

Devenish, B.J., Rooney, G.G., Webster, H.N., Thomson, D.J., 2010b. The entrainment rate for buoyant plumes in a crossflow. Boundary-Layer Meteorology 134, 411-439.

Dick, G.J., Anantharaman, K., Baker, B.J., Li, M., Reed, D.C., Sheik, C.S., 2013. The microbiology of deep-sea hydrothermal vent plumes: ecological and biogeographic linkages to seafloor and water column habitats. Frontiers in Microbiology 4, 79-94. 
Diez, F.J., Bernal, L.P., Faeth, G.M., 2005. PLIF and PIV measurements of the self-preserving structure of steady round buoyant turbulent plumes in crossflow. International Journal of Heat and Fluid Flow 26, 873-882.

Doron, P., Bertuccioli, L., Katz, J., Osborn, T.R., 2001. Turbulence characteristics and dissipation estimates in the coastal ocean bottom boundary layer from PIV data. J. Phys. Oceanogr. 31, 2108-2134.

Economidou, M., Hunt, G.R., 2009. Density stratified environments: the double-tank method. Exp. Fluids 46, 453-466.

Elderfield, H., Schultz, A., 1996. Mid-ocean ridge hydrothermal fluxes and the chemical composition of the ocean. Annu. Rev. Earth Planet. Sci. 24, 191-224.

Fischer, H.B., List, E.J., Koh, R.C.Y., Imberger, J., Brooks, N.H., 1979. Mixing in Inland and Coastal Waters. Academic Press.

Fortuin, J.M.H., 1960. Theory and application of two supplementary methods of constructing density gradient columns. Journal of Polymer Science 44, 505-515.

German, C.R., Lin, J., 2004. The thermal structure of the oceanic crust, ridge spreading, and hydrothermal circulation: How well do we understand their inter-connections? in: German, C.R., Lin, J., Parson, L.M. (Eds.), Mid-Ocean Ridges: Hydrothermal Interactions between the Lithosphere and Oceans. Geophysical Monograph 148, American Geophysical Union, pp. 1-18.

German, C.R., Von Damm, K.L., 2003. Hydrothermal processes, in: Turekian, K.K., Holland, H.D. (Eds.), Treatise on Geochemistry, Vol. 6: The Oceans and Marine Geochemistry. Elsevier, Oxford, pp. 181-222.

Ghajar, A.J., Bang, K., 1993. Experimental and analytical studies of different methods for producing stratified flows. Energy 18, 323-334.

Grafsrønningen, S., Jensen, A., Reif, B.A.P., 2011. PIV investigation of buoyant plume from natural convection heat transfer above a horizontal heated cylinder. Int. J. Heat Mass Transfer 54, 4975-4987.

Grant, H.L., Stewart, R.W., Moilliet, A., 1962. Turbulence spectra from a tidal channel. J. Fluid Mech. 12, 241-268. 
Helfrich, K.R., Battisti, T.M., 1991. Experiments on baroclinic vortex shedding from hydrothermal plumes. J. Geophys. Res.: Oceans 96(C7), 12511-12518.

Helfrich, K.R., Speer, K.G., 1995. Oceanic hydrothermal circulation: mesoscale and basin-scale flow, in: Humphris, S.E., Zierenberg, R.A., Mullineaux, L.S., Thomson, R.E. (Eds.), Seafloor Hydrothermal Systems: Physical, Chemical, Biological, and Geological Interactions. Geophysical Monograph 91, American Geophysical Union, pp. 347-356.

Hunt, G.R., Van den Bremer, T.S., 2011. Classical plume theory: 1937-2010 and beyond. IMA Journal of Applied Mathematics 76, 424-448.

Horner-Devine, A.R., 2006. Velocity, density and transport measurements in rotating, stratified flows. Exp. Fluids 41, 559-571.

Jiang, H., Breier, J.A., 2014. Physical controls on mixing and transport within rising submarine hydrothermal plumes: a numerical simulation study. Deep-Sea Research Part I: Oceanographic Research Papers 92, 41-55.

Launder, B.E., Spalding, D.B., 1972. Lectures in Mathematical Models of Turbulence. Academic Press.

List, E.J., 1982. Turbulent jets and plumes. Ann. Rev. Fluid Mech. 14, 189-212.

Lupton, J.E., Delaney, J.R., Johnson, H.P., Tivey, M.K., 1985. Entrainment and vertical transport of deep-ocean water by buoyant hydrothermal plumes. Nature 316, 621-623.

McDuff, R.E., 1995. Physical dynamics of deep-sea hydrothermal plumes, in: Humphris, S.E., Zierenberg, R.A., Mullineaux, L.S., Thomson, R.E. (Eds.), Seafloor Hydrothermal Systems: Physical, Chemical, Biological, and Geological Interactions. Geophysical Monograph 91, American Geophysical Union, pp. 357-368.

Middleton, J.H., 1986. The rise of forced plumes in a stably stratified crossflow. Boundary-Layer Meteorology 36, 187-199.

Morton, B.R., Taylor, G.I., Turner, J.S., 1956. Turbulent gravitational convection from maintained and instantaneous sources. Proc. R. Soc. London Ser. A 234, 1-23.

Mullineaux, L.S., France, S.C., 1995. Dispersal mechanisms of deep-sea hydrothermal vent fauna, in: Humphris, S.E., Zierenberg, R.A., Mullineaux, L.S., Thomson, R.E. (Eds.), Seafloor Hydrothermal Systems: Physical, Chemical, Biological, and Geological Interactions. Geophysical Monograph 91, American Geophysical Union, pp. 408-424. 
Nimmo Smith, W.A.M., Katz, J., Osborn, T.R., 2004. On the structure of turbulence in the bottom boundary layer of the coastal ocean. J. Phys. Oceanogr. 35, 72-93.

Osborn, T., 1980. Estimates of the local rate of vertical diffusion from dissipation measurements. J. Phys. Oceanogr. 10, 83-89.

Pham, M.V., Plourde, F., Kim, S.D., 2005. Three-dimensional characterization of a pure thermal plume. Transactions of the ASME 127, 624-636.

Pope, S.B., 2000. Turbulent Flows. Cambridge University Press.

Raffel, M., Willert, C.E., Wereley, S., Kompenhans, J., 2007. Particle Image Velocimetry: A Practical Guide. Springer-Verlag.

Reed, D.C., Breier, J.A., Jiang, H., Anantharaman, K., Klausmeier, C.A., Toner, B.M., Hancock, C., Speer, K., Thurnherr, A.M., Dick, G.J., 2015. Predicting the response of the deep-ocean microbiome to geochemical perturbations by hydrothermal vents. The ISME Journal 9, 1857-1869.

Rooney, G.G., Devenish, B.J., 2014. Plume rise and spread in a linearly stratified environment. Geophysical and Astrophysical Fluid Dynamics 108, 168-190.

Rudnicki, M.D., Elderfield, H., 1992. Theory applied to the mid-Atlantic ridge hydrothermal plumes: the finite-difference approach. J. Volcanol. Geotherm. Res. 50, 161-172.

Seol, D.G., Bhaumik, T., Bergmann, C., Socolofsky, S.A., 2007. Particle image velocimetry measurements of the mean flow characteristics in a bubble plume. J. Eng. Mech. 133, 665676.

Sharqawy, M.H., Lienhard, J.H., Zubair, S.M., 2010. Thermophysical properties of seawater: a review of existing correlations and data. Desalination and Water Treatment 16, 354-380.

Speer, K.G., Rona, P.A., 1989. A model of an Atlantic and Pacific hydrothermal plume. J. Geophys. Res. 94(C5), 6213-6220.

Steinbuck, J.V., Roberts, P.L.D., Troy, C.D., Horner-Devine, A.R., Simonet, F., Uhlman, A.H., Jaffe, J.S., Monismith, S.G., Franks, P.J.S., 2010. An autonomous open-ocean stereoscopic PIV profiler. J. Atmos. Oceanic Technol. 27, 1362-1380. 
Tagliabue, A., Bopp, L., Dutay, J.-C., Bowie, A. R., Chever, F., Jean-Baptiste, P., Bucciarelli, E., Lannuzel, D., Remenyi, T., Sarthou, G., Aumont, O., Gehlen, M., Jeandel, C., 2010. Hydrothermal contribution to the oceanic dissolved iron inventory. Nat. Geosci. 3, 252-256.

Tanaka, T., Eaton, J.K., 2007. A correction method for measuring turbulence kinetic energy dissipation rate by PIV. Exp. Fluids 42, 893-902.

Thurnherr, A.M., St. Laurent, L.C., 2012. Turbulence observations in a buoyant hydrothermal plume on the East Pacific Rise. Oceanography 25, 180-181.

Turner, J.S., 1973. Buoyancy Effects in Fluids. Cambridge University Press.

Turner, J.S., 1986. Turbulent entrainment: the development of the entrainment assumption, and its application to geophysical flows. J. Fluid Mech. 173, 431-471.

Turner, J.S., Campbell, I.H., 1987. Temperature, density and buoyant fluxes in "black smoker" plumes, and the criterion for buoyancy reversal. Earth Planet. Sci. Lett. 86, 85-92.

Von Damm, K.L., 1995. Controls on the chemistry and temporal variability of seafloor hydrothermal fluids, in: Humphris, S.E., Zierenberg, R.A., Mullineaux, L.S., Thomson, R.E. (Eds.), Seafloor Hydrothermal Systems: Physical, Chemical, Biological, and Geological Interactions. Geophysical Monograph 91, American Geophysical Union, pp. 222-247.

Watanabe, Y., Hashizume, Y., Fujisawa, N., 2005. Simultaneous flow visualization and PIV measurement of turbulent buoyant plume. Journal of Visualization 8, 293-294.

Webster, D.R., Brathwaite, A., Yen, J., 2004. A novel laboratory apparatus for simulating isotropic oceanic turbulence at low Reynolds number. Limnology and Oceanography: Methods 2, 1-12.

Willert, C.E., Gharib, M., 1991. Digital particle image velocimetry. Exp. Fluids. 10, 181-193.

$\mathrm{Xu}, \mathrm{D} ., \mathrm{Chen}, \mathrm{J} ., 2$ 2013. Accurate estimate of turbulent dissipation rate using PIV data. Experimental Thermal and Fluid Science 44, 662-672. 